\title{
SYNTHESIS OF BIFUNCTIONAL DIALKYL DISULFIDES FOR FABRICATION OF SURFACE OF GOLD AND APPLICATION TO ELECTROCHEMICAL SENSORS
}

\author{
KOJI NAKANO*, TEIJI TANIZAKI, HIROAKI TAIRA, and MAKOTO TAKAGI
}

Department of Chemical Science and Technology, Faculty of Engineering, Kyushu University, 6-10-1, Hakozaki, Higashi-ku, Fukuoka 812, Japan

\begin{abstract}
A new alkanethiol derivative containing a 18-crown-6 function (1) was introduced for fabrication of electrode surface. A 1-modified gold electrode was prepared by dipping in the solution of 1 . By using a $[\mathrm{Fe}(\mathrm{CN}) 6]^{3 / 4}$ redox couple as an electrochemical probe, a densely packed, electrochemically insulating surface layer formation by 1 was confirmed by cyclic voltammetry. This made the amperometric sensory application of the electrode difficult. On the other hand, this property suggested a possible application to chemical sensors with electrical impedance measurements. The idea was successfully demonstrated by sensing gaseous ammonia. Organic gases such as benzene and chloroform did not give response. The surfaceimmobilized crown ether played a key function in determining the selectivity.
\end{abstract}

Key word bifunctional alkanethiol, crown ether, self-assembling monolayer, electrical impedance, ammonia gas sensor

\section{INTRODUCTION}

Self-assembling, monolayer formation of long-chain, alkanethiols or disulfides on gold surfaces is of much current research interest[1]. This distinguished property of alkanethiols is expected to give a versatile, not too sophisticated means to functionalize electrode surface. From this viewpoint, we have been investigating a new class of compound, bifunctional dialkyl disulfides.

The structural features of the bifunctional dialkyl disulfides are as follows: The alkylthio group anchors the whole molecule via the formation of an inert coordination bond with metal surfaces. The long-chain methylene group serves as an insulator by forming a dense and stable molecular monolayer of alkyl chains, as well as a connector for an added functional group. A metal surface is thus covered with the functional groups with which we want to modify the Au surface eventually .

In the present study, Au electrode surface was modified with 1 . A potential utility of the modified electrode obtained was successfully demonstrated by its application to ammonia sensing.

\section{EXPERIMENTAL}

11-Mercaptoundecanoic acid[2] was oxidized with hydrogen peroxide to give disulfide, which was converted to the acid chloride and then condensed with hydroxymethyl 18-crown-6[3]. Compound 1-modified electrodes were prepared by immersing a Au disk or a $\mathrm{Ag}$ gauze into the dioxane solution of 1 ( $1 \mathrm{mM}$ ) for $24 \mathrm{hr}$ at room temperature. The electrodes were thoroughly washed with dioxane and were used for measurements. Cyclic voltammetry was performed on a Solartron Co. Model 1286 potentiostat with a conventional threeelectrodes design.

Figure 1 shows a construction of gas-sensing cell. The cell was mounted in an flow-through type glass vessel (volume, $1.2 \mathrm{dm}^{-3}$ ). Sample gas with known concentration of gaseous compounds (carrier, dry $\mathrm{N}_{2}$ ) was prepared by using a GASTEK Co. Model PD-1-B II Permeacal Permeater. All the flow lines of the cell were constructed with Teflon or glassware. Electrical impedance of the gassensing cell was monitored by a Wayne Kerr Co. Model

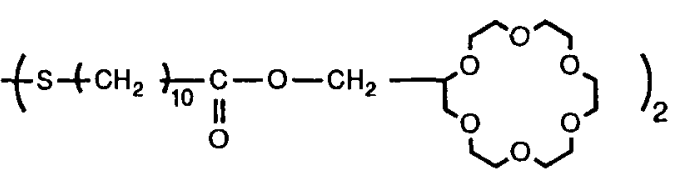


6425 Automatic Impedance Meter or by a Solartron Co. Model 1250A Frequency Response Analyzer with a two-electrodes configuration[4]. All experiments were made under constant temperature of $25^{\circ} \mathrm{C}$.

\section{RESULTS AND DISCUSSION}

The modified electrode was first characterized by cyclic voltammetry. A mirror-finished Au disk (diameter, 1.6 $\mathrm{mm}$ ) was modified with 1 . A platinum plate and a standard $\mathrm{Ag} / \mathrm{AgCl}$ (saturated $\mathrm{KCl}$ ) electrode were used as counter and reference electrode, respectively. The electrolyte solution was $0.1 \mathrm{M}$ Tetramethylammonium chloride containing $5 \mathrm{mM}$ each of $\mathrm{K} 3[\mathrm{Fe}(\mathrm{CN}) 6]$ and $\mathrm{K} 4[\mathrm{Fe}(\mathrm{CN}) 6]$.

The 1 -modified electrode showed a markedly different current-potential response when compared with a naked Au electrode. The peak currents due to the reversible electrode reaction of a $[\mathrm{Fe}(\mathrm{CN}) 6]^{3 / 4}$ system were less by a factor 0.4 than those at the bare electrode, and the shape of the current-potential response was nearly sigmoidal. These observations suggest formation of an electrochemically insulating, relatively dense layer of 1. A detailed study will be reported elsewhere.

Electrical response of the 1-modified $\mathrm{Ag}$ gauze electrode to gaseous ammonia is shown in Figure 2. Electrical impedance of the cell decreases according to the increase of ammonia concentration. The sensor gave a nearly reversible, steady-state response in a few minutes after exposure to sample gas. Cell impedance of the sensor to a $1 \mathrm{kHz}$ of sinusoidal-modulated waveform is nearly $10^{6} \Omega$. Thus, the magnitude of the respond to ammonia is not so large, but reproducibility was good. As shown in the figure, the sensor did not respond to such organic gases as benzene and chloroform. Needless to say, such electrical response to ammonia was not observed in case of an unmodified $\mathrm{Ag}$ electrode. The selectivity is most probably due to the host-guest interaction between the crown ether moiety and ammonia.

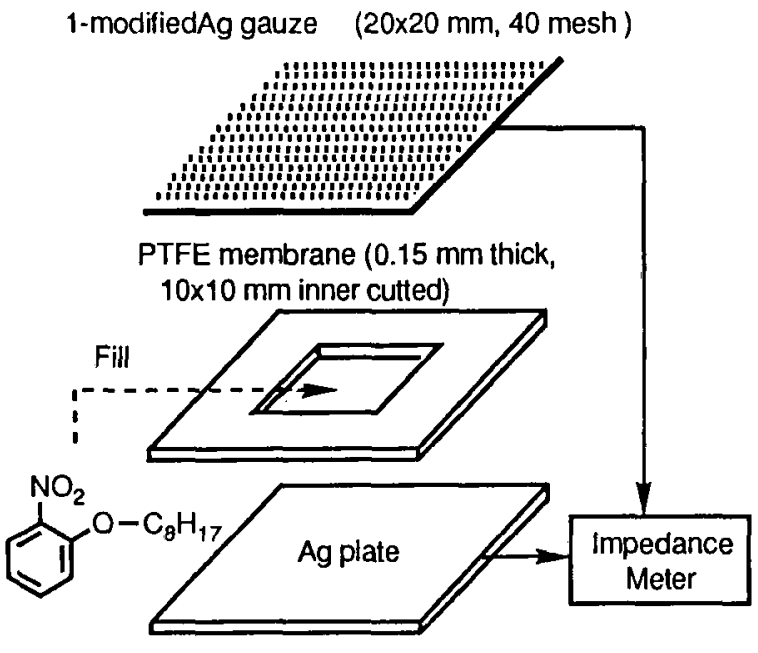

Figure 1 Cell Construction

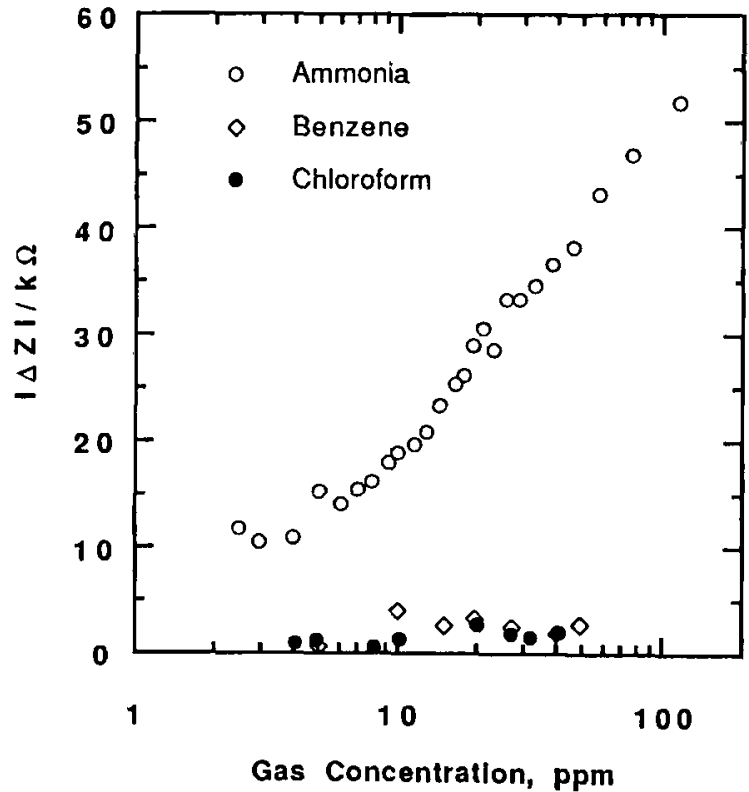

Figure 2 Electrical response to various gases A $1 \mathrm{kHz}$ of sinusoidal waveform was used for impedance measurement.

\section{REFERENCES}

1. (a)K. L. Prime, G. M. Whitesides, Science, 252, 1164 (1191) and references cited there in. (b)R. G. Nuzzo, L. H. Dubois, D. L. Allara, J. Am. Chem. Soc., 112, 558 (1990) and references cited there in.

2. (a)V. Boekelheide et al. eds.,Organic Synthesis Collection Volume 4, Wiley, New York, 1963, p. 401. (b)R. B. Wagner, H. D. Zook, Synthetic Organic Chemistry, Wiley, New York, 1965, p. 797.

3. D. M. Dishong, C. J. Diamond, M. I. Cinoman, G. M. Gokel, J. Am. Chem. Soc., 105, 586 (1983).

4. (a)J. R. Macdonald ed., Impedance Spectroscopy-Emphasizing Sold Materials and Systems, Wiley, New York, 1987. (b)A. E. G. Gass ed., Biosensors-A Practical Approach, IRL Press,Oxford, 1990, p.125. 